\title{
Optimum Design of an Air Tank for Fatigue and Fire Load
}

\section{Máté Petrik, Antal Erdős, Károly Jármai, Gábor Szepesi}

University of Miskolc, Institute of Energy Engineering and Chemical Machinery, Miskolc-Egyetemváros A/3 Building, 3515 Miskolc, Hungary

emails: petrik@uni-miskolc.hu, erdos@uni-miskolc.hu, jarmai@uni-miskolc.hu, szepesi@uni-miskolc.hu

\begin{abstract}
Pneumatic pressure vessels, or more commonly used names, air tanks, are used for storing compressed air to operate different pneumatic tools, for example, wrenches, grinders, sanders and others. The objective of design optimization of air tanks is cost reduction, by reducing the total mass of the vessel, the quantity of the welding seams with adequate strength and stiffness. This study describes the steps of this design optimization, but also deals with high cycle fatigue, to determine the lifetime of the equipment and the effect of the fire load. The optimization was made with the Generalized Reduced Gradient (GRG) method. Nozzles with the same geometry will have a different impact on the utilization, in the various diameters of shells. Therefore, the allowed number of cycles will change. The fire load was modelled as an ISO fire and corresponding temperature/pressure increase rates were investigated.
\end{abstract}

Keywords: pressure vessel; fire load; lumped model; optimization

\section{Introduction}

The transportation and storage of pressurized gases, such as methane or air, play an essential role in the economies of industrialized countries. Failure of these structures can cause fires or explosions, results in the contents flowing out and pollution of the environment, which can severely affect the company's production and have a detrimental effects on the environment. Most of the literature on this topic deals with pressure vessels containing liquid [1], where the authors have developed a new innovative approach to simulating pressurized vessels exposed to fire.

One of the most critical accidents is the fire exposure of pressure vessels. This may lead to catastrophic failure: explosion or the fireball effect. The severity of these events is influenced by energy accumulation during heating. The pressure inside the vessel increases as the temperature rises. Since the 1960s, there have 
been a number of experiments and measurements [2], that initially addressed safety issues. Nowadays, instead of the zonal models [3], the equations of heat quantities and mass equations are solved by computer.

Many researchers are studying the possibilities of optimization support frames in the event of a fire load. Farkas and Jármai [4] investigated cross-sections of welded square boxes for overall and local buckling with and without fire protection. Protected sections have been shown to be cheaper than unprotected sections. For the optimization, systematic search method was used. Jármai and Száva [5] modeled the local fires by cylindrical and conical discretization, and determined the temperature and the carrying capacity of rolled and welded Isections. Cabala and Jadlovsky [6] presented a multi-objective optimization method, which can be also acceptable to determine the minimal cross sections in case of a local fire.

In the event of fire in this equipment, the firefighters of the company extinguish the fire. Where possible, water is often used for cooling purposes, but that cooling affects the microstructure of the steel of which the pressure vessel and the supports are made. Thereafter, its mechanical properties will change (EN 100282), which affects the load-bearing capacity of the structure, especially under dynamic loads.

\section{Optimization}

The aim of the investigation involved an air tank with an internal volume of 1.5 $\mathrm{m}^{3}$. The sizing was based on EN 13445-3, which calculates the necessary wall thickness of the shell and the ends. The calculations were completed with different temperatures from $20^{\circ} \mathrm{C}$ to $400^{\circ} \mathrm{C}$. The ends of the vessel were chosen according to the DIN28011 standard, and the type was torispherical. The selected vessel material's (1.0425) yield strength and the tensile strength also depend on the temperature. The calculation of the given mechanical property is provided by the EN 10028-2 standard and the calculation was completed with linear interpolation. After determination of the geometry, the optimization was performed. The purpose of this method is to determine the optimal ratio between the height and the diameter of the pressure vessel to find the minimum weight and material cost of the vessel, where this ratio is a variable in the process. The constraints of the optimization were the volume of the vessel, which must be $1.5 \mathrm{~m}^{3}$ while the raising stress was less than the allowed stress. The range of the variable (H/D) was between 1 and 6. For this, the Microsoft Excel Solver Addition was used with the "Generalized Reduced Gradient" method. During the calculation, the yield strength and tensile strength reduction was considered due to the temperature increase. 


\section{Fire Load}

The fire which heats the pressure vessel can be a pool fire or a jet fire. In the event of a pool fire, a layer of a volatile liquid burns and a horizontal layer of fuel may float on a solid substance or on the surface of a liquid of a higher density. A jet fire is a turbulent diffusion flame that results from the combustion of fuel that is continuously released in a given direction. This article presents the pool fire mechanism, as a common problem in the chemical industry, since flammable substances can accumulate under pressure vessels.

\subsection{ISO Fire}

In this case, the amount of transferred heat is the effect of radiation and convection. According to the literature, the convection represents a smaller part, and the convective heat transfer coefficient $\left(\alpha_{c}\right)$ considerable with a value of 5-50 $\mathrm{W} / \mathrm{m}^{2} \mathrm{~K}$. However, the value of the radiative heat transfer coefficient $\left(\alpha_{\mathrm{r}}\right)$ highly depends on the temperature difference of the flame and the wall temperatures. To calculate this value, the flame temperature must be known. This temperature is determined as a function of time by the ISO 834 standard [7], shown in Figure 1:

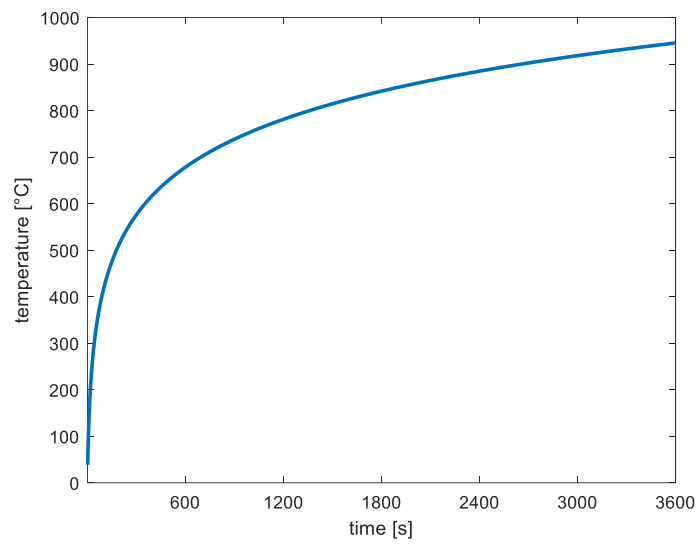

Figure 1

Standardized ISO 834 fire curve

\subsection{Radiative Heat Transfer Coefficient}

The following assumptions and simplifications are used to determine the radiative heat transfer coefficient in the case of a fire [8]:

- The properties of the fire are homogeneous in the volume examined. 
- The hot gases and the vessel are assumed to be grey.

- The surface of the pressure vessel is assumed to be opaque.

- The fire and the vessel surface are two infinitely parallel grey planes.

With these considerations, the value of the radiative heat transfer coefficient is

$$
\alpha_{R}=\frac{\varepsilon_{f} \varepsilon_{S}}{\varepsilon_{f}+\varepsilon_{s}-\varepsilon_{f} \varepsilon_{S}} \sigma\left[T_{f}^{2}(t)+T_{v}^{2}(t)\right]\left[T_{f}(t)+T_{v}(t)\right],
$$

where $\varepsilon_{f}$ is the emissivity of fire (assumed in the calculations to be 1), $\varepsilon_{s}$ is the emissivity of the surface (assumed to be 0.8 ), $\sigma$ is the Stefan Boltzmann constant $\left(5.67 \cdot 10^{-8} \mathrm{~W} / \mathrm{m}^{2} \mathrm{~K}^{4}\right), T_{f}$ is the temperature of the fire and $T_{v}$ is the temperature of the vessel (both expressed in $\mathrm{K}$ ). The radiative and convective heat transfer coefficient shall be used together as the resulting heat transfer coefficient:

$$
\alpha=\alpha_{c}+\alpha_{R}
$$

\section{Lumped Heat Capacity Model}

The lumped parameter model simplifies the complex three-dimensional model into a simple one-dimensional model. However, the lumped model has a strict applicability condition: The $B i$ number (Biot number, which describes the ratio of the heat transfer resistances inside of a body and at the surface of a body) must be less than 0.1 .

$$
B i=\frac{\alpha \cdot \frac{V}{A}}{\lambda}
$$

where $\lambda$ is the thermal conductivity of the wall (in $\mathrm{W} / \mathrm{mK}$ ), and $V / A$ is the characteristic thickness, which is the ratio of the cross-section and the perimeter (m). The higher the characteristic thickness, the lower the temperature of the specimen will be at the temperature of fire. The added problem is that not only the temperature of the vessel will change, but also, the temperature of the air inside the tank, which means that the pressure of the air will also increase, due to the combined gas law. Consequently, the internal heat transfer coefficient must be calculated from the inside with an empirical correlation of free convection. 


$$
N u=\left\{0.825+\frac{0.387 \cdot R a^{1 / 6}}{\left[1+\left(\frac{0.492}{\mathrm{Pr}}\right)^{9 / 16}\right]^{8 / 27}}\right\}^{2}
$$

Where, Ra number is the production of Gr number (Grashof number, which describes the ratio between the buoyancy to viscous force acting on the fluid) and Pr number (Prandtl number, which describes the ratio of momentum diffusivity to thermal diffusivity).

Based on these considerations, the heat flow from the fire to the wall of the vessel is

$\dot{Q}_{i n}(t)=\alpha(t) \cdot\left[T_{f}(t)-T_{v}(t)\right] \cdot A$,

and the heat flow from the vessel to the pressurized air is:

$\dot{Q}_{\text {out }}(t)=\alpha_{i}(t) \cdot\left[T_{v}(t)-T_{a}(t)\right] \cdot A$.

The average temperature increment of the vessel and the air using the lumped capacity heat method are:

$$
\begin{aligned}
& \Delta T_{v}(t)=\frac{\dot{Q}_{\text {in }}(t)-\dot{Q}_{\text {out }}(t)}{V_{v} \cdot \rho_{s} \cdot c_{p, s}(t)} \cdot \Delta t \\
& \Delta T_{a}(t)=\frac{\dot{Q}_{\text {out }}(t)}{V_{a} \cdot \rho_{a}(t) \cdot c_{p, a}(t)} \cdot \Delta t
\end{aligned}
$$

and in the $(t+1)$ time step the temperatures are:

$$
\begin{aligned}
& T_{v}(t+1)=T_{v}(t)+\Delta T_{v}(t) \\
& T_{a}(t+1)=T_{a}(t)+\Delta T_{a}(t)
\end{aligned}
$$

In Equations (4-10) the material properties of air $\left(\lambda_{a}, c_{p, a}, \rho_{a}\right.$ and $\left.\eta_{a}\right)$ depends on temperature and pressure, as well as, the properties of the steel, as a function of temperature.

Figure 2 and Figure 3 show that the specific heat and thermal conductivity highly temperature dependent and significant changes occur near the phase-change environment. The basic material properties for load-bearing calculations are the Young modulus and the yield strength, which temperature dependences are shown in Figure 4 according to the EN 1993.1.2:2005 [9] standard. 


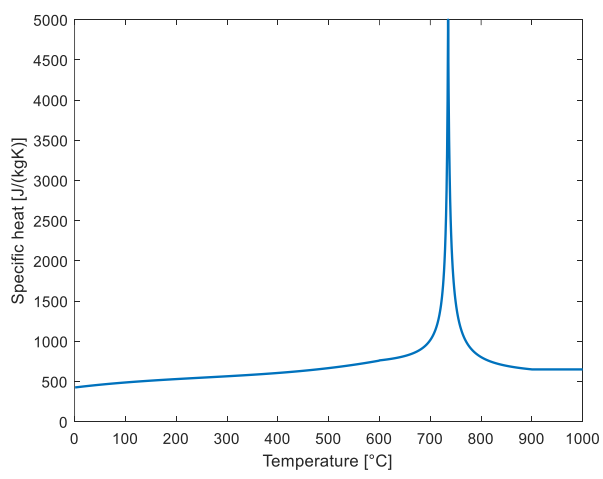

Figure 2

Temperature dependence of the specific heat of the Ferritic Steel

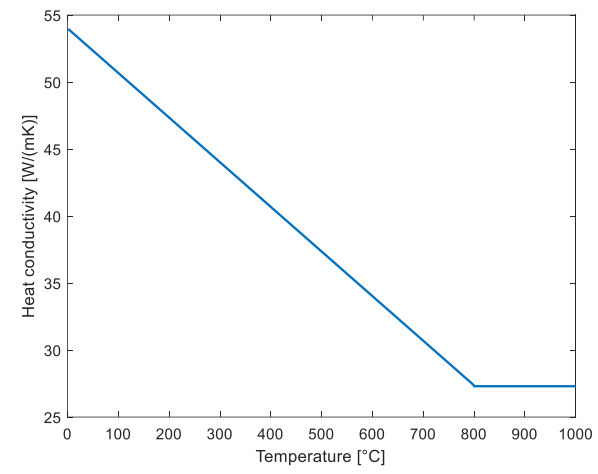

Figure 3

Temperature dependence of the heat conductivity of the ferritic steel

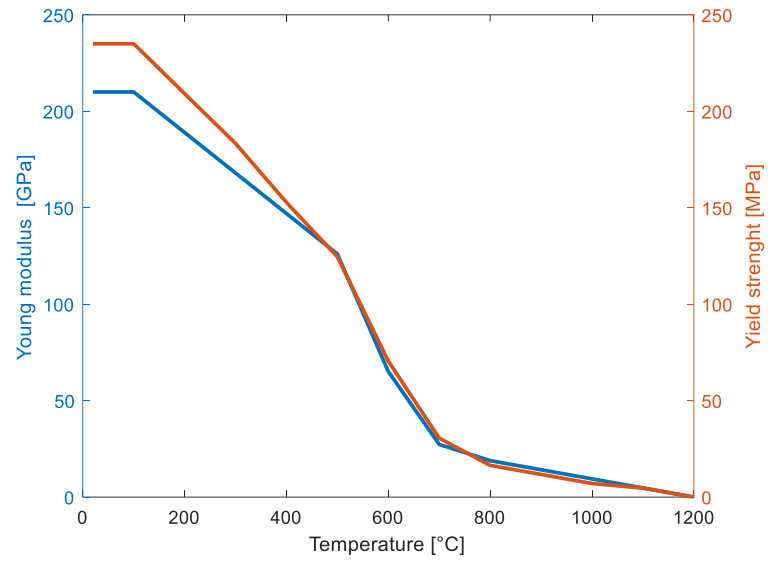

Figure 4

Mechanical properties of the steel 


\section{Results of the Calculations}

\subsection{The Heating Method}

First, the heating phase caused by the fire load is shown below. At first the fire load case was described. In this model a pressure relief valve is also involved with 9.0 bar $_{\mathrm{g}}$ set pressure and $1590 \mathrm{~mm}^{2}$ relief cross section. The calculation algorithm shown in Figure 5.

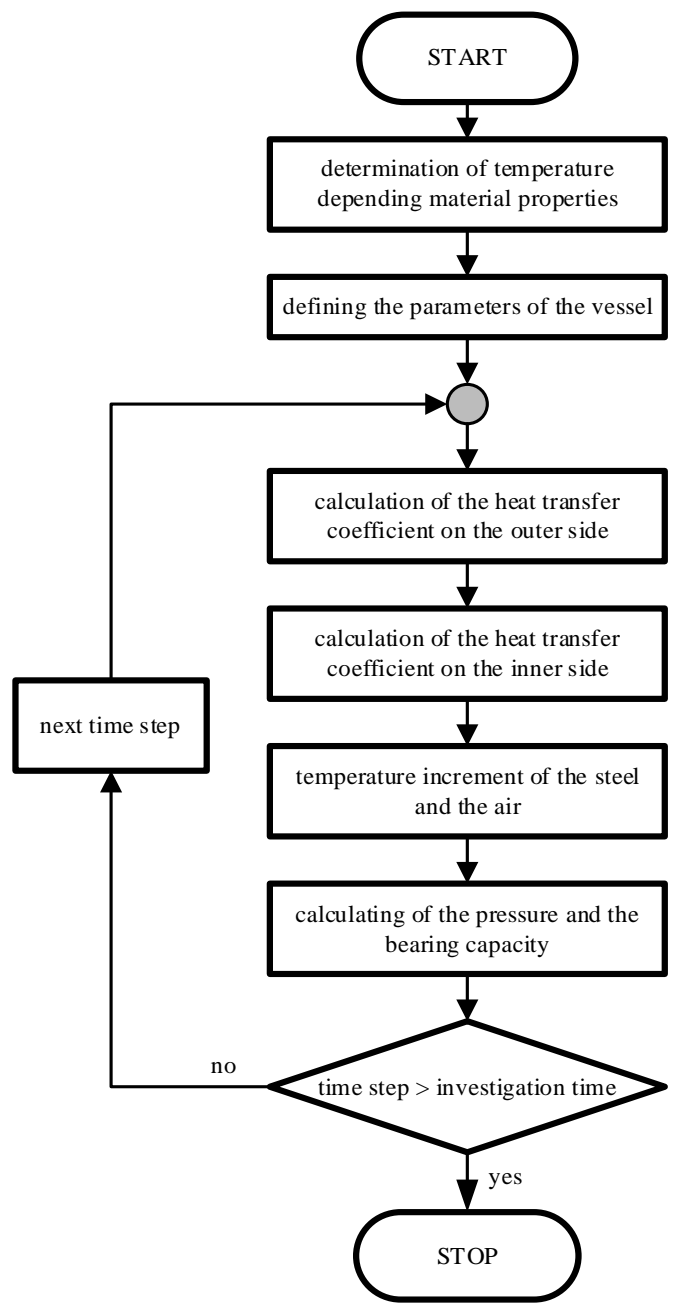

Figure 5

Algorithm of the fire load case 
Calculations were performed on the optimized vessel with the following dimensions.

Table 1

Dimensions of the optimized vessel

\begin{tabular}{|c|c|}
\hline External diameter & $950 \mathrm{~mm}$ \\
\hline Nominal wall thickness & $6 \mathrm{~mm}$ \\
\hline Cylinder length & $1900 \mathrm{~mm}$ \\
\hline Total volume & $1.512 \mathrm{~m}^{3}$ \\
\hline Heat transfer area & $6.517 \mathrm{~m}^{2}$ \\
\hline
\end{tabular}

Heat transfer processes are driven by the temperature difference, therefore knowing the temperature during the heating process is essential in the calculations. These are shown in Figure 6.

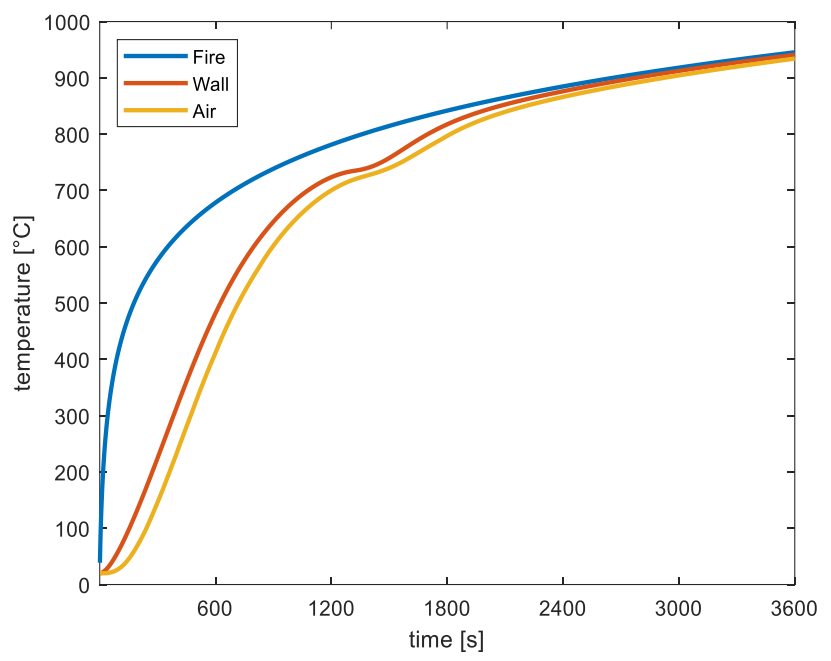

Figure 6

Temperatures of the vessel

Figure 7 shows the heat transfer coefficients on the internal $\left(\alpha_{i}\right)$ and external sides $(\alpha)$. The fluctuation of the internal side coefficient is the result of the operation of the relief valve. 


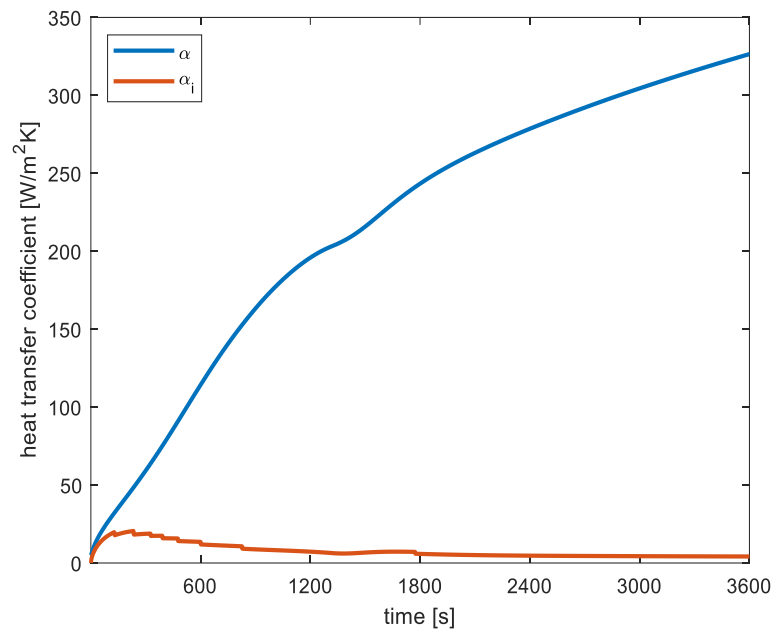

Figure 7

Heat transfer coefficients

With these geometrical parameters and material properties, the pressure of the air and the load-bearing capacity of the vessel shown in Figure 8.

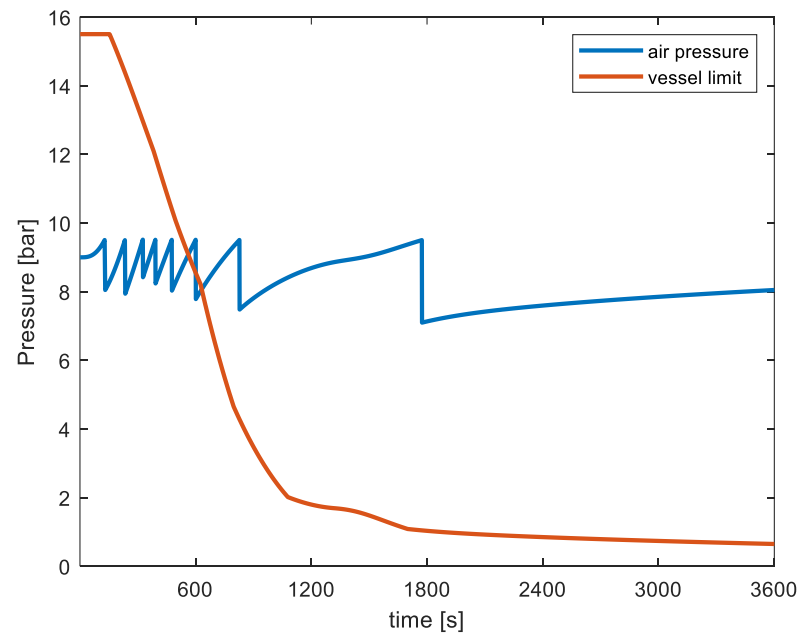

Figure 8

The pressure of air and load-bearing capacity

Figure 8 shows that considering the higher flame temperature, the heat flux from the flame to the vessel will be higher, and that will cause pressure increment, but due to the relief valve, the pressure should not exceed 9.5 bar. However, the material properties will decrease at higher temperatures, so the bearing capacity will also decrease. The moment the two graphs intersect, the vessel ruptures. 
In this case, this time is 562 seconds. Although this load-bearing capacity is directly proportional to the wall thickness, the load-bearing time will not be the same. Table 2 summarizes the times of investigated vessel with different wall thicknesses.

Table 2

Loading times with different wall thicknesses

\begin{tabular}{|c|c|}
\hline Nominal wall thickness (mm) & Load bearing time (s) \\
\hline 6 & 562 \\
\hline 8 & 717 \\
\hline 10 & 779 \\
\hline 12 & 904 \\
\hline 14 & 954 \\
\hline 16 & 996 \\
\hline
\end{tabular}

This can be explained by the fact that although the weight of the steel is higher, it has little effect on the temperature of the steel, but at such high temperatures, it has barely yield strength. The other fact is that the air has a relatively low specific heat; it warms up quickly and does not cool down the wall of the device. The behavior of a vessel filled with liquid, for example water, is quite different. Due to the higher mass and higher specific heat, the temperature rise is slower as the liquid cools the steel, so the failure occurs a longer time. An exception to this is a BLEVE (boiling liquid expanding vapor explosions) damaged vessel [10]. In this case, the liquid is in a liquid state at the beginning of the process; the temperature increases as a result of the heating. Nevertheless, the safety valve continuously decreases the pressure. This results in an operating state where the decreasing pressure forces the medium to change phase.

\subsection{The Cooling Method}

Accurate knowledge of the cooling process is just as important for the lifetime of the vessel as it is for heating. Cooling can cause a problem in two ways. During the heating process, the temperature rises, but due to the operation of the relief valve, the mass of the air has continuously decreased. As a result, cooling the warm and lower mass air to the initial temperature can result in lower pressure than the original, even in a vacuum, which can be dangerous to the device. Another problem is the cooling rate, because of the change of the microstructure of the steel. The P265GH steel is a weldable fine grained steel for pressure purposes with low carbon content. For this reason, the main criteria of the tempering was not fulfilled, since the carbon content is lower than $0.25 \%$. There is still a chance to the alteration of the microstructure. It is primarily an increase in hardness and thus a decrease in impact strength. So the steel of the vessel can become rigid, less resistant to the dynamic loads [11]. 
The appearance of the martensite can occur when the temperature rises above the A3 temperature of the steel, which is around $850^{\circ} \mathrm{C}$. The presence occurs when the cooling is fast enough, and it starts around $500^{\circ} \mathrm{C}$. In the case of firefighting, the cooling is continuous. Thus, the change in the microstructure can be followed with the non-equilibrium transformation diagram, also called as C-curve. The continuous cooling curve for hypo eutectoid steel is shown in Figure 9.

As shown in Figure 9, the martensite appears when the cooling rate exceeds about $500^{\circ} \mathrm{C} / \mathrm{s}$. During firefighting, this cooling rate is unreachable, so the risk of the appearance of the martensite is relatively low. However other steels such as P460NL1 or structural steels such as S355J2 that can be used materials for leg supports of the pressure vessel have higher carbon content, and it could be a relevant problem in case of cooling.

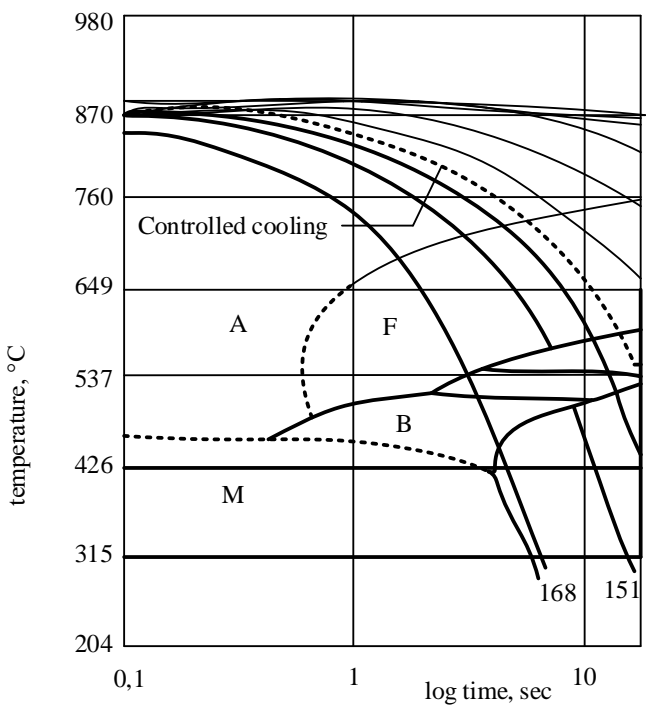

Figure 9

The relevant part of the CCT diagram for low carbon steel

Assuming that the cooling process is water cooling, the process can be divided into three parts, as shown in Figure 10.

In Phase 1 and 2, the wall temperature exceeds $100^{\circ} \mathrm{C}$, so the cooling water boils. Due to the high heat transfer coefficient caused by the boiling, the wall temperature will decrease. The first part is the shortest phase. In this case, the wall temperature is the highest of the three temperatures (that means despite cooling the wall heats the enclosed air in the vessel and boils the cooling fluid). 


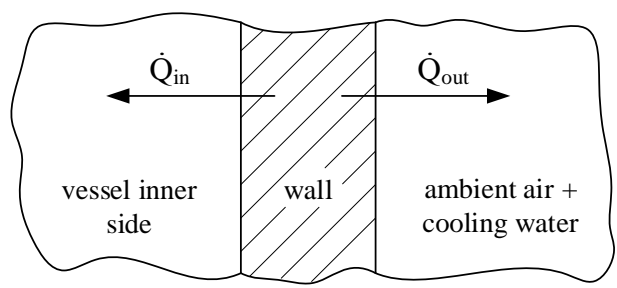

Phase 1

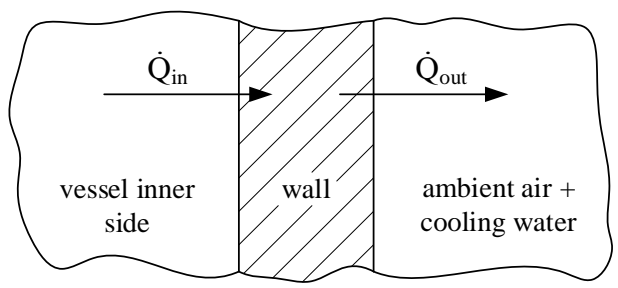

Phase 2 and 3

Figure 10

Phases of the cooling process

In the second part, the temperature of the air is higher than on the wall, so the direction of the heat flow is from the pressurized air to the ambient air (it is seen in Figure 10, Phase 2 and 3). In this case, the coolant fluid also boils because the wall temperature is higher than $100^{\circ} \mathrm{C}$. The time period is one order of magnitude greater than in Phase 1.

In Phase 3 the direction of the heat flow is the same as described in Phase 2, but there is no boiling effect on the outside as the wall temperature is below $100^{\circ} \mathrm{C}$. The value of the heat transfer coefficient is much smaller because there is no phase change. Considering these facts, the temperatures of the cooling section shown in Figure 11.

The other exciting and fundamental issue is the pressure of the air inside the vessel. Due to heating, the pressure increases with temperature. In order to hold the pressure and protect the vessel from harmful overpressure, the relief valve releases a certain amount of air. However, during cooling, the decreasing temperature also causes a pressure dependence. This is shown in Figure 12. 


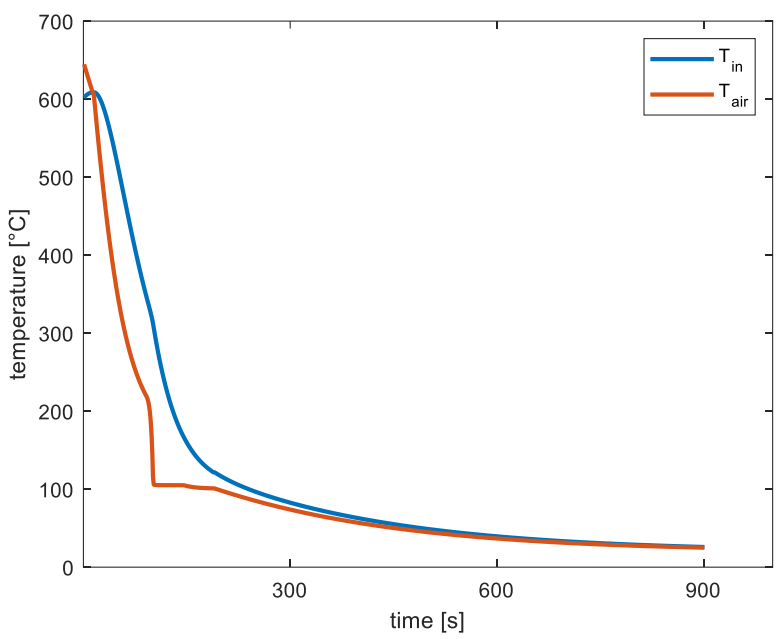

Figure 11

Temperatures during cooling

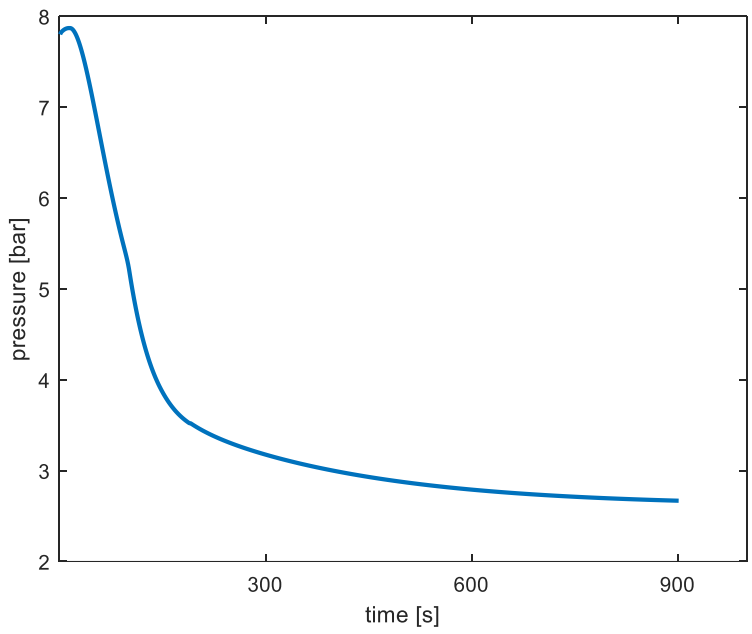

Figure 12

The pressure of air during cooling

It can be seen that this is not a problem, in this investigated case, but in the case of austenitic steel, where higher temperatures occur, the pressure inside the vessel can be vacuum at the end of the cooling, which can cause immediate failure.

\section{Conclusions}

The optimization of the tank was completed with the Solver Addition of Microsoft EXCEL to determine the optimal value of the ratio between the height and the diameter of the $1.5 \mathrm{~m}^{3}$ tank. The objective function was the cost of the material. 
This optimized tank has been investigated, in the event of a fire. The fire load used was a "pool" type fire with ISO 834 temperature-time function. Changes in mechanical and thermos-physical properties need to be considered. This is very important for calculating the heat transfer between steel and the internal and external phenomena. As the temperature rises, the pressure inside the tank is also increasing. To prevent the vessel from failing due to pressure, a safety valve was installed. The temperature of the shell also rises and the fire must be extinguished before the device collapses. The microstructure of the steel can also change. Martensite may appear after the fire, which reduces the strength of the steel. For this, the cooling rate is relatively high, higher than the cooling rate achievable by water extinguishing. Therefore, there is no significant change in the microstructure and the pressure vessel can be used after proper testing.

\section{Acknowledgement}

This research was supported by the European Union and the Hungarian State, cofinanced by the European Regional Development Fund in the framework of the GINOP-2.3.4-15-2016-00004 project, aimed to promote the cooperation between the higher education and the industry. The research was partially supported by the Hungarian National Research, Development and Innovation Office - NKFIH under the project number K 134358.

\section{References}

[1] I. R. Száva, I. Sebe, and K. Jármai, “Optimum Design of Vessel Supporting Frame for Fire," in MultiScience - XXX. microCAD International Multidisciplinary Scientific Conference, 2016, no. April, pp. 21-22

[2] G. A. Bray, "Fire protection of liquid petroleum gas storage tanks," Inst. Gas Eng. J., pp. 776-789, 1962

[3] K. W. Graves, "Development of a Computer Model for Modeling the Heat Effects on a Tank Car," US Dep. Transp. Fed. Railr. Adm. Washingt. DC, 1973

[4] J. Farkas and K. Jármai, "Minimum cost design for fire resistance of welded steel structures," J. Struct. Fire Eng., Vol. 1, No. 2, pp. 101-113, 2010

[5] K. Jármai and J. Száva, "International Institute of Welding Application of a virtual solid flame concept for fire resistance calculation of rolled and welded steel cross-sections at a local fire," 2019

[6] J. Čabala and J. Jadlovský, "Choosing the Optimal Production Strategy by Multi-Objective Optimization Methods," Acta Polytech. Hungarica, Vol. 17 , No. 5, pp. 7-26, 2020

[7] ISO-834

[8] C. Zhang and A. Usmani, "Heat transfer principles in thermal calculation of structures in fire," Fire Saf. J., Vol. 78, pp. 85-95, 2015 
[9] EN 1993.1.2: Design of steel structures - Part 1-2: General rules Structural fire design

[10] B. Hemmatian, J. Casal, E. Planas, and D. Rashtchian, "BLEVE: The case of water and a historical survey," J. Loss Prev. Process Ind., Vol. 57, No. July 2018, pp. 231-238, 2019

[11] A. Rose and H. Hougardy, Atlas of steels heat treatment. Düsseldorf: Verlag Stahleisen, 1972 